\title{
Analisis Usaha Tani dan Pola Tanam Komoditi Buah Naga (Hylocereus undatus) dan Lada (Piper Ningrum L) di Kecamatan Loa Janan Kabupaten Kutai Kartanegara
}

\section{Analysis of Farming and Planting Pattern Commodity Dragon Fruit (Hylocereus undatus) and Pepper (Piper Ningrum $\mathrm{L}$ ) in the District of Kutai Regency Loa Janan}

\author{
Zainudin $^{1}$ dan Akhmad Sopian ${ }^{1}$ \\ ${ }^{1}$ Tenaga Pedidik Program Studi Agroteknologi, Fakultas Pertanian, Universitas Widya Gama Mahakam \\ Jl. KH. Wahid Hasyim, Sempaja, Samarinda, Kalimantan Timur, Indonesia \\ email : ztjimpolo@gmail.com dan sopian063@gmail.com
}

Diterima : 17 Oktober 2016 Disetujui : 2 November 2016

\section{ABSTRACT}

\begin{abstract}
This research was conducted in order to obtain information system cropping patterns and farming in the District Loa Janan to increase cropping intensity in order to support the development of site-specific dryland farming insightful agribusiness. This research is also expected to result in the value of $R / C$ ratio greater than 1 so that it is economically feasible to be implemented at the farm level. This study aims to conduct inventory of characteristics of land such as: climate, relief, topography, soil type, and land use, mengidentivikasi pattern of farmers planting dragon fruit and pepper in the village Batuah, knowing the cost and farm income commodity dragon fruit and pepper, as well as determine the feasibility of farming based on the analysis of $R / C$ ratio. This research uses descriptive method with interviews with respondents sampled, namely farmers dragon fruit and pepper farmers in the village of Loa Janan Regency. The results showed by climatic conditions, topography and land more feasible to develop commodity pepper from the dragon fruit, both in monoculture and mixed farms. Overall analysis of farm commodities and pepper dragon fruit has a value of $R / C$ ratio $>1$, which means that the commodity still worth to be cultivated. Based on the analysis of capital productivity ( $\pi$ / C ratio) commodity pepper is more feasible to be developed because it is larger than bank interest, while the dragon fruit is smaller than bank interest. Based on the factors of production of farm commodities dragon fruit significant influence, such as land, seed and fertilizer.
\end{abstract}

Keyword: Farming, Planting Pattern, $R / C$ ratio

\section{PENDAHULUAN}

Sektor pertanian memiliki peranan yang cukup penting dan strategis dalam perekonomian daerah karena sektor pertanian tidak hanya berperan untuk menyediakan bahan pangan namun juga menjadi lapangan kerja dan sumber pendapatan bagi sebagian besar masyarakat Indonesia. Saat ini, pemerintah daerah mulai mengembangkan perekonomian masyarakat berdasarkan ketersediaan sumberdaya alam terbaharukan yakni sektor pertanian. Sektor pertanian adalah sektor yang sangat potensial karena dapat diperbaharui dan masih memungkinkan untuk dikembangkan secara maksimal di masa kini dan masa yang akan datang.

Pengembangan sektor pertanian ditandai dengan pengembangan komoditas unggulan dan teknologi pertanian. Lahan kering sangat potensial dikembangkan sebagai areal pertanian khususnya di Kecamatan Loa Janan Kabupaten Kutai Kartanegara, akan tetapi pengembangan pertanian di lahan kering menghadapi berbagai kendala, antara lain : ketersediaan air, kandungan bahan organik, kemasaman tanah dan unsur hara yang rendah merupakan faktor pembatas yang dapat mempengaruhi pertumbuhan dan hasil tanaman bila mengusahakan suatu komoditas di lahan tersebut.

Upaya yang dapat dilakukan untuk memecahkan masalah yang dihadapi petani lahan kering adalah mengembangkan teknologi usahatani yang sesuai dengan kondisi setempat. Rekayasa model pengelolaan usahatani lahan kering spesifik lokasi diharapkan dapat menjadi model pengembangan lahan kering berkelanjutan dengan berwawasan agribisnis. Pendekatan model sistem usahatani lahan kering berkelanjutan dapat memberikan peluang untuk meningkatkan dan memantapkan pendapatan petani melalui pemanfaatan sumberdaya lahan lebih efisien dan efektif serta memperhatikan kelestarian sumberdaya lahan secara berkesinambungan.

Peningkatan produktivitas usahatani dalam rangka peningkatan pendapatan petani dapat dilakukan dengan pengaturan pola tanam. Pola tanam adalah pengaturan penggunaan lahan pertanaman dalam kurun waktu tertentu. Pola tanam dapat diterapkan dengan tujuan memanfaatkan sumberdaya secara optimal dan untuk menghindari resiko kegagalan panen. Pola 
tanam dapat juga digunakan sebagai landasan untuk meningkatkan produktivitas lahan. Biasanya, pengelolaan lahan sempit untuk mendapatkan hasil/pendapatan yang optimal maka dilakukan pendekatan pertanian terpadu, ramah lingkungan, dan semua hasil tanaman merupakan produk utama adalah pendekatan yang bijak.

Berdasarkan uraian diatas bahwa dalam rangka memperoleh informasi sistem pola tanam

\section{BAHAN DAN METODE}

Penelitian ini dilakukan selama kurang lebih 3 bulan, mulai Juli hingga September 2016. Metode yang digunakan dalam penelitian ini adalah metode deskriptif. Penelitian meliputi tahapan survei dan wawancara kepada petani buah naga dan lada yang dijadikan sampel. Pengambilan sampel menggunakan purposive sampling yaitu metode penetapan sampel dengan berdasarkan pada kriteria-kriteria tertentu, dalam hal ini peneliti melakukan pengambilan sampel berdasarkan sebaran

\section{HASIL DAN PEMBAHASAN}

\section{Pola Tanam Buah Naga dan Analisis Usaha Tani}

\section{a. Pola Tanam Buah Naga}

Budidaya tanaman buah naga merupakan bagian dari rotasi tanaman yang selama ini dikembangkan oleh masyarakat desa Batuah yaitu rambutan-buah naga-lada. Pola tanam untuk tanaman buah naga di Desa Batuah dan usaha tani di Kecamatan Loa Janan untuk peningkatan intensitas pertanaman guna mendukung pengembangan usahatani lahan kering spesifik lokasi berwawasan agribisnis. Penelitian ini juga diharapkan dapat menghasilkan nilai $\mathrm{R} / \mathrm{C}$ ratio yang lebih besar dari 1 sehingga layak secara ekonomi untuk diterapkan di tingkat petani.

tanaman buah naga dan tanaman lada pada lahan kering di Kecamatan Loa janan. Kuesioner lengkap yang berisikan keterangan mengenai kondisi keluarga dan usahatani petani dilengkapi berdasarkan sebaran pertanaman buah naga dan lada. Hasil kuesioner ini digunakan untuk melihat penyebaran lokasi budidaya tanaman buah naga dan tanaman lada untuk analisis usaha tani lahan kering di Kecamatan Loa Janan.

Penelitian dilaksanakan di Kecamatan Loa Janan yang merupakan lahan kering yang secara administratif termasuk wilayah Kabupaten Kutai Kartanegara, Kalimantan Timur.

Tabel 1. Pola Tanam dan Luas Lahan Usahatani Buah Naga

\begin{tabular}{|c|l|c|}
\hline No & \multicolumn{1}{|c|}{ Pola Tanam } & $\begin{array}{c}\text { Luas rata-rata } \\
\text { usaha tani (Ha) }\end{array}$ \\
\hline 1. & Monokultur Buah Naga & 1 \\
\hline 2. & Kebun Campuran: Durian dan Buah Naga & 0,5 \\
\hline 3. & Kebun Campuran: Kelapa Sawit, Rambutan dan Buah naga & 0,5 \\
\hline 4 & Kebun Campuran:Rambutan, Buah naga dan Lada & 0,5 \\
\hline
\end{tabular}

Kecamatan Loa Janan bervariasi sesuai dengan kondisi lahan dan topografi serta ketinggian tempat di wilayah tersebut. Pola tanam buah naga yang dominan diusahakan disajikan pada tabel di bawah ini:
Sumber : Data Primer, 2016

Pola pertanaman secara monokultur usaha tani buah naga oleh masyarakat desa Batuah dilakukan karena merupakan tanaman buah utama, luas pertanaman buah naga secara monokultur rata-rata $1 \mathrm{Ha} /$ petani. Pemilihan pola tanam monokultur disebabkan karena belum banyak tersedia sarana produksi seperti bibit dan juga untuk lebih memudahkan dalam pemeliharaan tanaman. Pola tanam yang lebih mendominasi adalah pola tanam kebun campuran antara tanaman buah dan tanaman perkebunan lain sehingga luas lahan masing- masing pertanaman sangat kecil yaitu rata-rata $0,5 \mathrm{Ha} /$ petani.

Kebun campuran merupakan pola tanam yang paling dianjurkan pada tanah-tanah mineral Kalimantan, terutama pada lahan yang memiliki kemiringan yang curam sebab sistem kebun campuran dapat memberikan manfaat untuk tanaman yang dibudidayakan karena adanya perbaikan antara lain :

1. Sumber bahan organik, serasah dari pepohonan dan hasil pangkasan cabang dan ranting yang dikembalikan ke permukaan 
tanah dapat menjadi sumber bahan organik untuk dapat menggemburkan tanah.

2. Menekan gulma dengan adanya naungan kanopi tanaman tahunan
3. Memperbaiki porositas tanah

4. Menjaga kestabilan iklim mikro

5. Mengurangi bahaya erosi.

\section{b. Analisis Usaha Tani Buah Naga}

Tabel 2. Analisis Usaha Tani Buah Naga

\begin{tabular}{|c|c|c|c|}
\hline No & Uraian & Per 0,5 Ha & Per 1 Ha \\
\hline \multirow[t]{4}{*}{1.} & Modal Per Musim Tanam & & \\
\hline & Tanah & 1.500 .000 & 3.000 .000 \\
\hline & Alat-Alat & 150.000 & 150.000 \\
\hline & Total & 1.650 .000 & 3.150 .000 \\
\hline \multirow[t]{4}{*}{2.} & Produksi/Penerimaan & & \\
\hline & Produksi total @ 4 kg x 500 pohon & 2000 & 4000 \\
\hline & Harga jual Petani $(\mathrm{Rp} / \mathrm{Kg})$ & 5000 & 5000 \\
\hline & Nilai Produksi/Penerimaan Total & 10.000 .000 & 20.000 .000 \\
\hline \multirow[t]{8}{*}{3.} & Biaya Produksi & & \\
\hline & Benih per batang@ 5000 x 500 pohon & 2.500 .000 & 5.000 .000 \\
\hline & NPK Phonska (250 kg x @ 10.000) & 2.500 .000 & 5.000 .000 \\
\hline & Pupuk Organik (1000 kg x@ 350 kg) & 350.000 & 700.000 \\
\hline & Herbisida (1 botol x 75.000) & 750.000 & 1.500 .000 \\
\hline & Biaya PBB (Rp) & 20.000 & 20.000 \\
\hline & Biaya penyusutan alat & 2500 & 2500 \\
\hline & Total Biaya (Rp) & 6.122.500 & 12.245.000 \\
\hline 4. & Pendapatan Petani (Rp) & 3.877 .500 & 7.755 .000 \\
\hline \multirow[t]{12}{*}{5.} & Keuntungan & & \\
\hline & Tenaga Kerja (100.000/HOK) & & \\
\hline & Pengolahan tanah (3 Orang) & 600.000 & 1.200 .000 \\
\hline & Penanaman (3 Orang) & 300.000 & 600.000 \\
\hline & Pemupukan (3 Orang) & 300.000 & 600.000 \\
\hline & Pemeliharaan & 250.000 & 500.000 \\
\hline & Panen & 600.000 & 1.200 .000 \\
\hline & Total Upah Tenaga Kerja & 2.050 .000 & 4.100.000 \\
\hline & Total Upah Tenaga Kerja (HOK) & 20.5 & 41 \\
\hline & Sewa Lahan Milik Sendiri & 1.500 .000 & 3.000 .000 \\
\hline & Bunga Modal Milik Sendiri (12\%) & 198.000 & 396.000 \\
\hline & Keuntungan & 129.500 & 259.000 \\
\hline
\end{tabular}

Sumber: Data Primer, 2016

Berdasarkan tabel analisis usahatani buah naga diatas dapat dilihat bahwa produksi buah naga per usahatani cukup besar yaitu mencapai $2.000 \mathrm{~kg}$, akan tetapi adanya penurunan harga jual buah naga yang terjadi akhir-akhir ini menyebabkan penerimaan petani cukup rendah. Rendahnya harga jual buah naga kemungkinan disebabkan adanya panen raya sehingga mengakibatkan jatuhnya harga buah naga selain itu, juga dapat diakibatkan belum adanya industri buah naga di Kalimantan Timur.
Penerimaan petani pada budidaya buah naga yang rendah tentu saja berpengaruh terhadap keuntungan yang diperoleh petani. Petani masih mengeluarkan biaya produksi yang cukup tinggi pada budidaya buah naga sehingga keuntungan yang diperoleh sangat rendah.

Tenaga kerja yang digunakan pada budidaya buah naga masih menggunakan tenaga kerja keluarga karena kegiatan budidaya masih bisa ditangani oleh keluarga. 


\section{c. Analisis R/C}

Berdasarkan analisis kelayakan $\mathrm{R} / \mathrm{C}$ rasio suatu usahatani buah naga dikatakan layak jika $\mathrm{R} / \mathrm{C}>1$

\begin{tabular}{|l|r|r|}
\hline & Per UT (0,5 ha) & \multicolumn{1}{|c|}{ Per 1 ha } \\
\hline Nilai Produksi (R) & 10.000 .000 & 20.000 .000 \\
\hline Total Biaya (C) & 6.122 .500 & 12.245 .000 \\
\hline Pendapatan (R-C) & 3.877 .500 & 7.755 .000 \\
\hline Upah tenaga kerja keluarga (W) & 2.050 .000 & 4.100 .000 \\
\hline Total tenaga yang dicurahkan (HOK) & 20.5 & 41 \\
\hline Keuntungan & 129.500 & 259.000 \\
\hline Nilai sewa lahan & 1.500 .000 & 3.000 .000 \\
\hline
\end{tabular}

1. $R / C$ rasio $=\frac{R p 10.00 .000}{\operatorname{Rp} 6.122 .500}=1,6$

2. $\pi /$ C rasio $=\frac{\mathbb{R p} 129.500}{\mathbb{R p} 6.122 .500}=2,11 \%$

3. Produktivitas tenaga kerja : $\frac{\text { Fo } 10.000000}{20,5}=487.804 / \mathrm{HOK}$

4. Pendapatan petani $>$ sewa lahan

Berdasarkan analisis diatas terdapat tiga parameter yang membuat usahatani buah naga layak untuk dikembangkan, akan tetapi berdasarkan analisis $\Pi / \mathrm{C}$ rasio maka usahatani

\section{Pola Tanam Lada dan Analisis Usaha Tani}

\section{a. Pola Tanam Lada}

Tanaman lada mulai berproduksi pada tahun keempat dengan masa produktif berlangsung sampai dengan tahun kesepuluh, hasil lada pada tahun selanjutnya sudah tidak memadai. Buah lada hitam siap dipanen 7-8 bulan setelah pembungaan dengan ciri butir buah sudah mencapai ukuran normal, keras sukar buah naga tidak layak untuk dikembangkan karena produktivitas modal lebih kecil dari bunga bank yang berlaku.

Tabel 3. Pola Pertanaman Lada

\begin{tabular}{|c|l|c|}
\hline No & \multicolumn{1}{|c|}{ Pola Pertanaman } & Luas rata-rata Usahatani (ha) \\
\hline 1 & Monukultur lada & 0,5 \\
\hline 2 & Kebun campuran (Durian + Lada) & 0,5 \\
\hline 3 & Kebun campuran (Kelapa, Pisang, dan Lada & 0,5 \\
\hline 4 & Kebun campuran (Rambutan, Buah Naga, dan Lada & \\
\hline
\end{tabular}

Sumber: Data Primer, 2016

Pola tanam untuk budidaya lada di Desa Batuah bervariasi yaitu ada yang mengembangkan dengan sistem monokultur dan juga dengan kebun campuran. Berdasarkan syarat tumbuh tanaman lada dan juga pengamatan di desa Batuah bahwa tanaman lada dihancurkan tangan, dan berwarna hijau sampai kekuning-kuningan. Masa panen berlangsung mulai bulan Juni sampai dengan Oktober dengan produktivitas lada selama umur produktif berkisar antara 0,37-0,70 ton/ha/tahun dimana hasil tertinggi dicapai pada tahun ke enam. lebih baik dikembangkan dengan pola kebun campuran, karena tanaman lada merupakan tanaman merambat dan menginginkan tidak terkena terpaan angin langsung karena akan menyebabkan kerontokan buah pada fase generatif. 


\section{b. Analisis Usahatani Lada}

Tabel 4. Analisis Usaha Tani Tanaman Lada Per Musim Tanam

\begin{tabular}{|c|c|c|c|}
\hline No & Uraian & Per 0,5 ha & Per 1 ha \\
\hline & Modal Per Musim Tanam & & \\
\hline & Tanah & 1.500 .000 & 3.000 .000 \\
\hline & Alat-alat & 150.000 & 150.000 \\
\hline & Total & 1.650 .000 & 3.150.000 \\
\hline \multirow[t]{4}{*}{1} & Total Produksi & & \\
\hline & Produksi total (kg) & 750 & 1500 \\
\hline & Harga $(\mathrm{Rp} / \mathrm{kg})$ & 70000 & 70000 \\
\hline & Total Produksi & 52.500 .000 & 105.214.000 \\
\hline \multirow[t]{10}{*}{2} & Biaya Produksi & & \\
\hline & Benih (kg) Varietas Bangkok & 750.000 & 1.500 .000 \\
\hline & Urea (150 Kg x @ 15.000) & 2.250 .000 & 4.500 .000 \\
\hline & NPK Phonska (510 kg x @10.000) & 5.100 .000 & 10.200 .000 \\
\hline & Pupuk Organik (1000 kg x @ 350) & 350.000 & 700.000 \\
\hline & Herbisida (1 btl x 75.000) & 750.000 & 1.500 .000 \\
\hline & Biaya PBB (Rp) & 20.000 & 20.000 \\
\hline & Biaya Penyusutan alat (cangkul) & 2500 & 2500 \\
\hline & Tiang Pancang & 5.625 .000 & 11.250 .000 \\
\hline & Total Biaya (Rp) & 14.847.500 & 29.695 .000 \\
\hline 3 & Pendapatan Petani (Rp) & 37.652.500 & 75.305 .000 \\
\hline \multirow[t]{13}{*}{4} & Keuntungan & & \\
\hline & Tenaga Kerja & & \\
\hline & Pengolahan tanah (4 Orang) & 800.000 & 1.600 .000 \\
\hline & Penyemaian & 250.000 & 500.000 \\
\hline & Penanaman (3 Orang) & 300.000 & 600.000 \\
\hline & Pemupukan (3 Orang) & 300.000 & 600.000 \\
\hline & Pemeliharaan & 250.000 & 500.000 \\
\hline & Panen & 800.000 & 1.600 .000 \\
\hline & Total upah tenaga kerja keluarga & 2.700 .000 & 5.400 .000 \\
\hline & Total Tenaga Kerja (HKO) & 27 & 54 \\
\hline & Sewa lahan milik sendiri & 1.500 .000 & 3.000 .000 \\
\hline & Bunga modal milik sendiri (12\%) & 198.000 & 396.000 \\
\hline & Keuntungan & 35.453.500 & 70.907.000 \\
\hline
\end{tabular}

Keterangan : Biaya Penggunaan tenaga kerja $=100.000 / \mathrm{HKO}$

Sumber : Analisis Data Primer,2016

Berdasarkan tabel diatas dapat diketahui bahwa jenis teknologi produksi yang telah diterapkan petani dalam budidaya ini merupakan teknologi yang telah meluas penggunaannya baik dalam hal bibit, pupuk, dan input lainnya. Dalam budidaya lada selain penggunaan pupuk kimia, petani juga menggunakan pupuk organik berupa pupuk kandang, hal ini menandakan bahwa petani telah memahami bahwa penggunaan pupuk organik akan memberikan dampak positif bagi tanah yang akan menjamin keberhasilan usaha budidaya lada.

Penggunaan tenaga kerja dalam usahatani lada masih menggunakan tenaga kerja keluarga, hal ini karena tenaga kerja keluarga masih bisa menangani keseluruhan proses budidaya lada sehingga penggunaan tenaga kerja luar masih tidak dibutuhkan.

Sistem budidaya lada di Desa Batuah keuntungan yang diperoleh petani memang sangat besar yaitu Rp 35.453.500. Keuntungan ini diperoleh setelah 3 tahun kegiatan budidaya, artinya selama tiga tahun petani harus mengeluarkan modal yang cukup besar untuk biaya produksi, akan tetapi setelah panen maka peluang usahatani lada cukup menjanjikan dalam hal keuntungan karena harga lada yang cukup tinggi dipasaran dan ditingkat petani. 


\section{c. Analisis R/C}

Berdasarkan analisis kelayakan $\mathrm{R} / \mathrm{C}$ rasio suatu usahatani lada dikatakan layak jika $\mathrm{R} / \mathrm{C}>1$

\begin{tabular}{|l|r|r|}
\hline & Per UT (0,5 ha) & \multicolumn{1}{|c|}{ Per 1 ha } \\
\hline Nilai Produksi (R) & 52.500 .000 & 105.214 .000 \\
\hline Total Biaya (C) & 14.847 .500 & 29.695 .000 \\
\hline Pendapatan (R-C) & 37.652 .500 & 75.305 .000 \\
\hline Upah tenaga kerja keluarga (W) & 2.700 .000 & 5.400 .000 \\
\hline Total tenaga yang dicurahkan (HOK) & 27 & 54 \\
\hline Keuntungan & 35.453 .500 & 70.907 .000 \\
\hline Nilai sewa lahan & 1.500 .000 & 3.000 .000 \\
\hline
\end{tabular}

1. RC rasio $=\frac{\operatorname{Rp} 52.500 .000}{R_{p} 14.847 .500}=3,53$

2. $\pi / \mathrm{C}$ rasio $=\frac{\operatorname{Rp}_{p} 35.453 .500}{\operatorname{Rp}_{p} 14.847 .500}=283 \%$

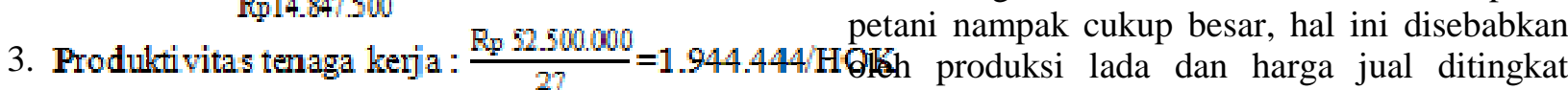
petani cukup tinggi.

Berdasarkan hasil perhitungan keempat kriteria tersebut maka usahatani lada layak untuk dikembangkan di Desa Batuah. Pendapatan
petani nampak cukup besar, hal ini disebabkan

4. Pendapatan petani $>$ sewa lahan

\section{KESIMPULAN}

1. Berdasarkan kondisi iklim, topografi dan tanah lebih layak untuk mengembangkan komoditi lada dari pada buah naga, baik secara monokultur maupun kebun campuran.

2. Secara keseluruhan analisis usaha tani komoditas buah naga dan lada mempunyai nilai $\mathrm{R} / \mathrm{C}$ ratio > 1, yang berarti bahwa komoditas tersebut masih layak untuk dibudidayakan.

3. Berdasarkan analisis produktivitas modal $(\pi / \mathrm{C}$ ratio) komoditas lada lebih layak

\section{DAFTAR PUSTAKA}

Daniel. 2004. Pengantar Ekonomi Pertanian. Bumi Aksara. Jakarta.

Direktorat Jenderal Perkebunan dan Institut Pertanian Bogor. 1993. Pedoman Pembibitan dan Pembuatan Kebun Perbanyakan Tanaman Lada.

Kadariah. 1988. Evaluasi Proyek Analisis Ekonomi. LPEE UI. Jakarta.

Rayes. 2006. Metode Inventarisasi Sumberdaya Lahan. Penerbit Andi. Yogyakarta.

Soekartawi. 1986. Ilmu Usahatani dan Penelitian Untuk Pengembangan Petani dikembangkan karena lebih besar dari bunga bank, sedangkan buah naga lebih kecil dari bunga bank.

4. Berdasarkan faktor-faktor produksi usaha tani komoditas buah nga berpengaruh secara signifikan, seperti luas lahan, bibit dan pemupukan.
Kecil. Penerbit Universitas Indonesia. Jakarta.

Singarimbun dan Effendi. 1989. BAHAN DAN METODE Survai. LP3ES. Jakarta.

Soetriono. 2006. Pengantar Ilmu Pertanian. Bayumedia. Malang.

Suratiyah. 2006. Ilmu Usaha Tani. Penebar Swadaya. Jakarta.

Tohir. 1991. Seuntai Pengetahuan Usaha Tani Indonesia. PT. Rineka Cipta. 